\title{
Case Study: The Effect of Low Carbohydrate Energy Restricted Diet on Body Composition and Physical Performance of a Female Artistic Gymnast
}

\author{
Aleksandar Markov, Tatyana Dzimbova* \\ South-West University “Neofit Rilski”, Blagoevgrad, Bulgaria
}

DOI: $10.36348 /$ jaspe.2020.v03i02.002 | Received: 05.02.2020 | Accepted: 12.02 .2020 | Published: 14.02 .2020

*Corresponding author: Tatyana Dzimbova

\section{Abstract}

Physics of a gymnast is very important for appearance on the competition, but also is crucial for performance, as an extra weight decreases the ability to perform certain movements and leads to injuries. The aim of the study was to reduce body weight of young female gymnast with minimum losses of muscle mass changing diet. Nineteen years old gymnast was involved in the study. Nutrition was examined using food questionnaire and food records. Body impedance analyzer Ioi 353 was used for body composition analysis and Heath-Carter method - for somatotype determination. Wingate and Sargent test were applied for anaerobic capacity determination. A low carbohydrate energy restricted nutritional plan for five days was developed. The subject reduced her weight by $2.1 \mathrm{~kg}$. Her anaerobic capacity did not change significantly according to Wingate test (relative average power $2^{\text {nd }}$ visit $-6 \mathrm{~W} / \mathrm{kg}$ and $5^{\text {th }}$ visit $-6.22 \mathrm{~W} / \mathrm{kg}$ ), but according to Sargent test $\left(2^{\text {nd }}\right.$ visit $-3345.6 \mathrm{~W}$ and $5^{\text {th }}$ visit $\left.-4252 \mathrm{~W}\right)$ her power increased. The results clearly show that the person reduced the weight for about one month and the largest percentage being due to the loss of body fat and this did not affect the anaerobic capacity of the gymnast.

Key words: gymnastics, weight maintenance, anaerobic capacity.

Copyright @ 2020: This is an open-access article distributed under the terms of the Creative Commons Attribution license which permits unrestricted use, distribution, and reproduction in any medium for non-commercial use (NonCommercial, or CC-BY-NC) provided the original author and source are credited.

\section{BACKGROUND}

The artistic gymnastics is an Olympic sport that involves exercises that require balance, strength, flexibility, agility, coordination and endurance. The movements associated with gymnastics contribute to the development of muscle groups on the hands, legs, shoulders, back, chest and abdomen. The apparatuses used by men and women have differences, as there are apparatuses that are only for men or women. Female's artistic gymnastics includes 4 apparatuses: vault, uneven bars, balance beam, and floor. Gymnastics require explosive sprinting, jumping, pushing and pulling skills together with balance and artistic. On vault, balance beam and floor the explosive force of the legs plays an important role in the connecting elements and the acrobatic series. Jumping is one of the most important movements in floor combinations and vaults and is developed by gymnasts at an early age as part of daily training [1].

The appearance is of a great importance for the performance. It is important not only from the point of view of the referee and the coach, but it is also essential for gymnastics. Physics is of particular importance for the ability to perform certain movements and extra pounds would lead to difficulties and, in some cases, injuries. To be successful, a gymnast must meet certain characteristics of the body [2]. Over the years there have been major changes in the bodies of successful gymnasts, with the current tendency to have small bodies and small body weight [3]. Although some differences have been found in different gymnastics studies, the main characteristic of the gymnastics somatotype [4] is mesomorphy, i.e. sufficiently developed muscle mass. For the most part, elite gymnasts are defined as ecto-mesomorphic. The somatotype is usually used for comparing elite and nonelite gymnasts [5] and is regarded as one of the key factors for the success.

Modern artistic gymnastics requires greater strength and power because of increasing technical difficulty required through revision of the International Gymnastics Federation (FIG) Code of Points [6]. Gymnasts are encouraged from an early age to learn more difficult skills to ensure a higher start value on the 
competition. This shows that it is very important for the gymnast to develop his anaerobic metabolism earlier. Currently, there is no specific ergometer test to assess gymnasts, but as a golden standard Wingate test could be useful for estimation their mechanical power.

\section{Presentation of the Athlete}

She was a 19 years old gymnast. After graduated high school, she stopped the gymnastics training for several months and had prepared for the exams at the university where she was admitted. She practiced gymnastics at the gymnastics club in a small town. She was admitted into the University in the capital. It was not possible to exercise regularly, which led to the accumulation of extra pounds. In recent months, she seriously considered restoring form and returning to gymnastics. She was able to overcome the initial stress at the university and adjusted her busy curriculum with training. She entered gradually with training on the days off from study - Friday, Saturday and Sunday. However, the weight gained made her less flexible and impeded her good performance. She was motivated to regain her form and join the next national championship. She came with a desire to change her current state.

The aim was to reduce body weight with minimum losses of muscle mass with a help of changes in a diet.

\section{Overview of Interventions}

After being informed of all procedures the gymnast gave written consent. The study was performed in accordance with the principles outlined in the Declaration of Helsinki and the South-West University Research Ethics Committee.

\section{Body Composition Assessment and Somatotyping}

Prior to the study, the subject was asked to abstain from physical activity, food, and fluid intake. Weight and height were measured as well as body composition with bioelectric impedance analyzer Ioi 353. The somatotype was determined using the HeathCarter method, with three skin folds (triceps, subscapular, supraspinale), two diameters (humerus, femur) and two circumferences (arm and calf). The measurement was carried out five times, at the same time (morning at 10 o'clock), every week on Friday.

\section{Nutrition Assessment}

The subject completed a nutrition questionnaire [7], as well as maintained a food records for the foods she consumed in 5 consecutive days (in these days weekends were included). She was preinstructed to write any food and drink she consumed, and to report its quantity as accurately as possible. When the food was homemade, the recipe for its preparation is also described. The data from the questionnaire were processed using pre-prepared formulas that calculate the total energy, as well as the amounts of protein, carbohydrates and fats in the normal diet of the subject. Food logs were processed in the ASA24 system of the National Cancer Institute (https://asa24.nci.nih.gov) by us. The vitamin and mineral reference values had been adjusted by me in accordance with the Ordinance on the Physiological Nutrition Standards of the population of Bulgarian Ministry of Health promulgated on 01/22/2018.

\section{Wingate Test}

The test was performed with a Monarch $828 \mathrm{E}$ bicycle ergometer. The system includes a bicycle ergometer and software. The test involved 30 seconds of maximum load on the leg. After 5 minutes of warmup, which involved sprinting at different loads, the subject stopped for a three-minute recovery. The test started with maximum speed rotation without any load. After reaching the maximum pedal speed, a fixed weight of $7.5 \%$ of the weight of the subject was applied. The pedalling with this weight lasted for 30 seconds, striving for maintaining the maximum speed of pedalling, respectively maximum power. After the end of the test, peak power was determined for 5 seconds. This represented the maximum power that a person could develop in the first 5 seconds. The relative maximum power was determined by dividing the maximum power by the subject's weight. The device also allowed determining the average power for 30 seconds. The test was performed twice on the second and on the last visit.

\section{Determination of the lactate in the blood}

The measurement was performed with the biochemical analyzer BIOSEN C Line of the German company EKF Diagnostic. The determination of the lactate in the blood is based on electrochemical measurement with a chip sensor. The sample was aspirated and entered into the system automatically. The sample contained L-lactate, which is converted by enzyme (which is immobilized into the chip sensor) to pyruvate to form hydrogen peroxide. It released free electrons that generate electrical current that was registered by the electrode of the device. The electrical signal obtained is proportional to the concentration of lactate in the sample. Samples were taken in $20 \mu \mathrm{l}$ capillaries, which were placed in a microtube with hemolysing solution (dilution 1:51). The sample was a capillary blood.

\section{Sargent Test}

Sargent test, also known as vertical jump, is suitable for tracking the development of elastic leg strength. The test is easy to perform as the equipment is extremely affordable and inexpensive. All we need is a wall, a centimeter and chalk. The athlete warmed-up for 10 minutes. She stood against the wall and extended her hand, indicating the position in $\mathrm{cm}$ of the stretched arm (M1). Then, from a static position, the subject jumped as high as possible, extending her hand again and touching the wall (M2). Three consecutive jumps were 
made and the highest value was taken. The difference M2-M1 in cm was determined. The test was performed twice on the second visit and on the last visit.

\section{Data Analysis}

Mean values and standard deviations of the variables were calculated using descriptive statistics. Excel was used to process and analyze the nutrition data. A spread sheet for calculating the results of the questionnaire was prepared in Excel. Formulas were introduced to calculate total energy intake with food, protein, carbohydrates and fats. The experimental data on blood lactate concentration before and after the Wingate test were presented as individual values for each attempt.

\section{Study protocol}

The gymnast came to the research center seven times during the study from $1^{\text {st }}$ of March to $12^{\text {th }}$ of April. The first visit was to meet each other, to exchange contact information and to talk about diet and its assessment, her food preferences and choices. We informed her about the study and what we intend to do with her data and she signed the informed consent. She filled in the food questionnaire and got instructions how to keep her dietary records and the way she should send them to us. On a second visit her anthropometric data and skin folds, humerus and femur diameters, and arm and calf circumferences were measured. Capillary blood was taken to determine lactate concentrations prior to loading. She was relieved to take a light snack as the heavy Wingate test was then forthcoming. Our experience showed that when individuals take the test, they should not be hungry. The test led to a severe decrease in the blood glucose concentration when the person is hungry, which could even result in a seizure after the test. After a short break, the person returned to perform the remaining tests. Because the Wingate test requires the greatest effort, the study began with it. Before the test five minutes warm up on a bicycle ergometer was performed. After the test, the gymnast relaxed, during which time the results of the nutrition questionnaire and the food records were discussed and initial recommendations were made. A goal to achieve in terms of kilograms was set. Then, the Sargent test was performed. Third visit was only to give her a nutrition plan for 5 days and to instruct her how to combine meals in the plan in order to use it for a longer period of time. We scheduled the next meetings every Friday at 10 a.m. (four times) in the center to track body changes with anthropometric measurements. On the last meeting along with anthropometric measurements she performed again the Wingate and Sargent test.

\section{Outcome of the intervention}

Body composition parameters such as body weight, body fat mass and soft lean mass (as it is much closer to muscle mass) and somatotype determination were the two methods we used for monitoring changes during the study. There were five visits in the center with body measurements and they are presented in the Table-1.

Table-1: Anthropometric data of the subject with height $159 \mathrm{~cm}$

\begin{tabular}{|l|l|l|l|l|l|l|}
\hline Visit & Weight, kg & M.B.F., kg & L.B.M., kg & S.L.M., kg & B.M.I., kg/m & Fatness, $\%$ \\
\hline $1^{\text {st }}$ & 61.6 & 17.7 & 43.9 & 40.4 & 24.4 & 10.8 \\
\hline $2^{\text {nd }}$ & 61.1 & 16.9 & 44.2 & 40.7 & 24.2 & 9.9 \\
\hline $3^{\text {rd }}$ & 60.8 & 17.1 & 43.7 & 40.3 & 24 & 9.4 \\
\hline $4^{\text {th }}$ & 60.5 & 16.7 & 43.8 & 40.3 & 23.9 & 8.8 \\
\hline $5^{\text {th }}$ & 59.5 & 16.4 & 43.1 & 39.7 & 23.5 & 7 \\
\hline Diference $\left(5^{\text {th }}-1^{\text {st }}\right.$ visit) & 2.1 & 1.3 & 0.8 & 0.7 & 0.9 & 3.8 \\
\hline
\end{tabular}

M.B.F. - Mass of Body Fat, L.B.M. - Lean Body Mass, S.L.M. - Soft Lean Mass, B.M.I. - Body Mass Index

As you can see from the table at first measurement, the gymnast`s weight was $61.6 \mathrm{~kg}$ with her $159 \mathrm{~cm}$, her fat was $17.7 \mathrm{~kg}$ and her fatness was $10.8 \%$. At the end of the study these values were respectively: weight $-59.5 \mathrm{~kg}$, fat mass $-16.4 \mathrm{~kg}$ and fatness $-7 \%$. Fatness is the ratio of current weight to standard weight. The decrease of $2.1 \mathrm{~kg}$ could be seen. This decrease in body weight affected mostly the fat mass $(1.3 \mathrm{~kg}$ lower) than the muscle mass $(0.7 \mathrm{~kg})$.

During the study along with body composition measurements somatotype components were determined. The subject started with the following somatotype components 4.1-6.6-1.0 and she changed the numbers with 3.3-5.8-1.2 at her last visit. The mesomorphic type is the type that is characteristic for gymnastics, as shown in a number of studies (PoblanoAlcalá \& Braun-Zawosnik, 2014; SterkowiczPrzybycien \& Gualdi-Russo, 2019; Massidda et al.,
2013). The most important result from the applied diet is that her endomorphic components of the somatotype decreased with 0.8 , while the ectomotphy increased with 0.2 . This result was very important for us as the endomorphy describes the relative degree of adiposity of the body and its decrease showed the loss of body fat mass. Although mesomorphic component also decreased it is still predominant. This was another prove that the body composition was changing during the intervention period.

Two methods were used to examine gymnast's nutritional status: a nutrition questionnaire and food records. The questionnaire is short and gives an idea of the amounts of the essential nutrients and of the total energy intake with food. The results of the questionnaire show that she normally consumes 1807 $\mathrm{kcal} /$ day, with the corresponding amount of protein 85 $\mathrm{g}$, carbohydrates - $300 \mathrm{~g}$ and fat - $52 \mathrm{~g}$. These data 
indicate that gymnast's diet perfectly provides her daily energy needs and could not lead to the desired weight loss. As the physical activity is not very high at the moment, this additionally justifies paying attention to the food intake and making some changes. After preliminary conversations, subject had taken food reductions herself, and her food records showed that she had reduced her energy intake far below what is needed. The analysis of the five-day records showed that the person received different amounts of food on different days. The analysis was done in asa24. We took in to account that in different regions of the planet foods contain different amounts of macronutrients and micronutrients, but this analysis provides a basic idea of a person's nutritional trends and could help to analyze the potential deficiency of a substance over a longer period of time. The analysis made from the obtained data shows that the person does not receive enough of most of the basic minerals and vitamins (Figure-1, blue line).

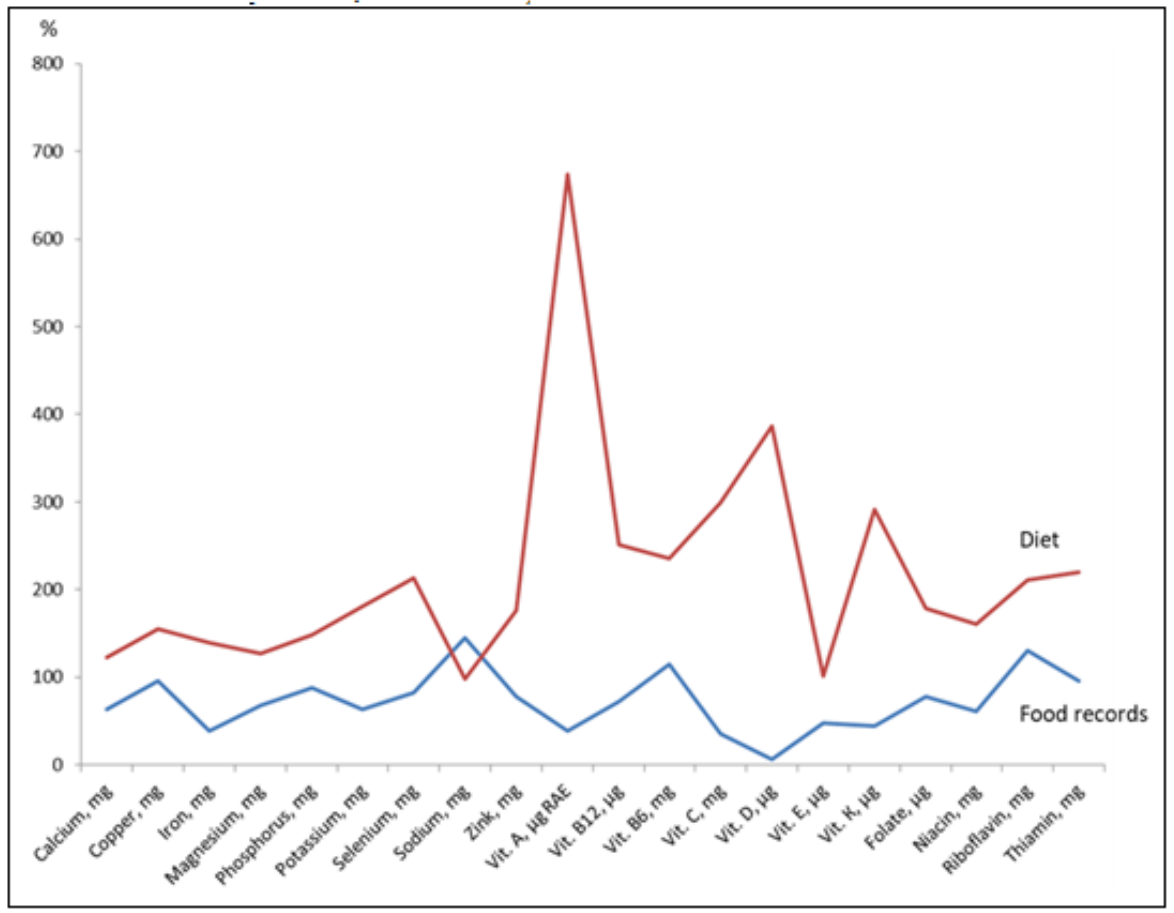

Fig-1: Percentage of daily needs of mineral and vitamins

As could be seen from Figure-1, the person managed to satisfy with the diet only vitamin B6 and riboflavin. The remaining vitamins and minerals were not sufficiently present in the consumed food, and for some of them the amounts were extremely insufficient. The idea of newly developed nutrition plan was along with correcting energy intake to manage to ensure proper mineral and vitamin intake.

Some recommendations were made after meeting with the subject. We explained her in an understandable language the benefits of adequate nutrition and the role of each mineral and vitamin in the body and the problems associated with their long-term deficiency. The gymnast received a detailed description of it on paper, which she could read at any time. This document contains both information about the role of the substance and sources from which it could be obtained in large quantities. We discussed the different nutritional preferences of the gymnast, as well as outlined the key points of the daily nutrition and ways to adjust the diet.

We prepared a nutritional plan that provided a daily amount of energy of $1711 \pm 175 \mathrm{kcal} / \mathrm{d}$. (27 $\mathrm{kcal} / \mathrm{kg}, 1.4 \mathrm{~g} / \mathrm{kg}$ protein, $3.2 \mathrm{~g} / \mathrm{kg}$ carbohydrates, and 1 $\mathrm{g} / \mathrm{kg}$ fat daily) (Table 2). Three main meals were included in the diet - breakfast, lunch and dinner, as well as two snacks one morning and one afternoon accompanied with freshly squeezed orange juice. The main products included in the diet were fruits and vegetables, in accordance with the taste preferences of the subject. Foods traditionally presented in Bulgarian menu were also included to make it easier for her and her mother to provide the right food. The analysis of the composition of the food was done in advance using the database at www.bb-team.org, which contains a wide range of traditional foods. The nutritional plan was prepared for 5 days and its advantage was the possibility of different combinations of staple meals as they are interchangeable. If necessary, it was also possible to consume some additional food (we provided her some additional choices) which should be reported. She did not use this possibility. We communicated with a gymnast all the time in order to make some corrections and to avoid misreporting of food consumed. Finally, we had a nutritional plan with low carbohydrates but providing all necessary vitamins and minerals, adequate energy and the subject was satisfied 
with it. As it shown on figure 1 (red line) the newly developed plan could ensure all macro- and micronutrients over $100 \%$. The amount of vitamin A was very high almost $700 \%$ of daily needs as it is presented in large quantities in fruits and vegetables in the menu, but it was still far lower than the maximum allowed quantity of $7500 \mu \mathrm{g}$. According to the Ordinance on the Physiological Nutrition Standards of the population of Bulgarian Ministry of Health the need of vitamin $\mathrm{D}$ is $15 \mu \mathrm{g}$ daily. The reason for this is that the country is located at latitude $41^{\circ} 14^{\prime}$ north, i.e. the synthesis of vitamin D during the winter months under the influence of sunlight is impossible, so adequate intake of vitamin D with food was necessary. Another argument for this amount was that gymnastics is an indoor sport and additionally does not ensure a proper sunlight for its synthesis. Iron was the element of our priority as some studies showed that it is a very important element that should be monitoring at female gymnasts [8]. Women need more iron than men.

The purpose of the present study was both a healthy weight loss and the preservation of the physical fitness of the gymnast. The main characteristic of gymnastics is the relatively high anaerobic capacity and especially the explosive power of the lower limbs. Elements of gymnastics include a large number of jumps. As can be seen from Table 1, the change in muscle mass is $0.7 \mathrm{~kg}$, which is about $33.33 \%$ of the total weight lost. Most of the weight loss is due to the loss of body fat (about $61.09 \%$ ).

Table-2: Total energy values and essential nutrients in the usual diet and nutritional plan (Diet) prepared by us

\begin{tabular}{|l|l|l|l|}
\hline & Food records & Food questionnaire & Diet \\
\hline Total energy intake $(\mathrm{TEI}), \mathbf{k c a l} / \mathbf{d}$ & 1693 & 1807 & 1711 \\
\hline Protein intake, $\mathbf{g}$ & $54.4(12.85 \%$ of TEI $)$ & $85.07(18.83 \%$ of TEI $)$ & $89.47(20.92 \%$ of TEI $)$ \\
\hline Carbohydrate intake, $\mathbf{g}$ & $279.35(65.99 \%$ of TEI $)$ & $250.81(55.52 \%$ of TEI $)$ & $199.63(46.67 \%$ of TEI $)$ \\
\hline Fat intake, $\mathbf{g}$ & $39.8(21.16 \%$ of TEI $)$ & $51.5(25.65 \%$ of TEI $)$ & $61.62(32.41 \%$ of TEI $)$ \\
\hline
\end{tabular}

Along with the diet changes the gymnast gradually entered the normal training regime. During the week she was not able to do gymnastics training, but for that reason she run daily for 1 hour (four hours per week), as well as spent 1 hour in the gym (four days, general physical training), working on different parts of her body. Fridays, Saturdays and Sundays she had a normal gymnastics training (5 training sessions with duration 2 hours), which consists of perfecting different elements and preparing combinations for the upcoming national championship. Comparing to the other teammates she had no day off, as they have one free of training day, she had more hours general training (32 hours versus 30 hours of general training of the team per month) and the same 40 hours of sport specific training per month. She needed this amount of general training as she had to increase her physical activity in order to help weight loss for shorter time without too many food restrictions. On the other hand, physical activity helped not to lose too much muscle mass during the period of diet changes.

In order to check if the muscle strength was compromise during food changes, we used two anaerobic tests. Currently, the Wingate anaerobic test in a laboratory setting on a cycle ergometer is accepted as golden standard for determining anaerobic performance. This test determines the anaerobic capacity, which is extremely important in gymnastics. Most of the exercises required both technique and great explosive force.

To check the anaerobic strength of the lower limbs of the subject, a Wingate test was performed at the beginning of the study (second visit) and at the last visit of this study cycle. The results of this test are presented in Table-3.

Table-3: Power (peak, relative peak, average and relative average), anaerobic fatigue and lactate concentrations as a results of Wingate test

\begin{tabular}{|l|l|l|l|l|l|l|l|l|l|}
\hline Visit & $\mathbf{P P}, \mathbf{W}$ & $\mathbf{R P P}, \mathbf{W} / \mathbf{k g}$ & $\mathbf{A P}, \mathbf{W}$ & $\mathbf{R A P}, \mathbf{W} / \mathbf{k g}$ & $\mathbf{A F}, \boldsymbol{\%}$ & \multicolumn{4}{|l|}{ Lactate, $\mathbf{m m o l} / \mathbf{l}$} \\
\cline { 6 - 9 } & & & & & & Before & $\mathbf{1}^{\text {st }} \mathbf{m i n}$ & $\mathbf{3}^{\text {rd }} \mathbf{m i n}$ & $\mathbf{5}^{\text {th }} \mathbf{m i n}$ \\
\hline $2^{\text {nd }}$ & 484.88 & 7.82 & 371.98 & 6 & 37.00 & 2.35 & 9.19 & 10.19 & 10.53 \\
\hline $7^{\text {th }}$ & 453.47 & 7.69 & 367.26 & 6.22 & 27.20 & 2.4 & 8.59 & 10.75 & 11.13 \\
\hline
\end{tabular}

$\mathrm{PP}$ - peak power, RPP - relative peak power, AP - average power, RAP - relative average power, AF - anaerobic fatigue.

As can be seen from the results, the maximum and average power, as well as the relative maximum power, decreased slightly with the decrease of kilograms, while the relative average power increased slightly. Of course, we cannot talk about statistically significant differences, since we have only two measurements, but from these results it could be concluded that if the anaerobic power of the lower limbs was not increased at least it was not significantly affected by weight loss. A positive aspect of weight loss is a decrease in the rate of anaerobic fatigue, which decreases by $9.8 \%$ at the second measurement. This is probably due mainly to two factors: first, reduced weight, and second, increased anaerobic capacity. There is only little evidence on anaerobic abilities in elite gymnasts, regardless the extensive testing being 
performed, e.g. by the Wingate test [9]. The data from the Wingate test evidenced in elite gymnasts by Inbar et al., [10] corresponded to $12.3 \mathrm{~W} . \mathrm{kg}^{-1}$ for the RPP, but the test in most cases is performed with lower fixed weight of $6 \%$ of body weight so we could not compare her results with literature.

Another indicator of anaerobic capacity is the blood lactate concentration after the Wingate test. The results are presented in Table-3.

Higher lactate concentrations indicate greater capacity for anaerobic metabolism. Blood lactate concentration was highest at $5^{\text {th }}$ minute after the test in both measurements, with the concentration significantly higher in the second measurement. Increased volume of exercises of the gymnast since the beginning of the study affected her anaerobic capacity, as well as increased the ability of the muscles to tolerate higher concentrations of lactate.

The second test (Sargent test) is also suitable for assessment of the explosive power of the lower limbs [11]. The test was conducted three times, taking the best achievement. On the second visit, the gymnast achieved a result of $43 \mathrm{~cm}$, while the result achieved on her $7^{\text {th }}$ visit was $47 \mathrm{~cm}$. A heavier person who jumps at the same height as the lighter should do more work because he has a bigger mass to move, so it is very convenient to calculate power as a criterion for the jump. It is recommended [12] to use the Sayers formula [13] that takes into account, in addition to the height of a vertical jump (VJ) and weight (mass) of the subject:

Peak power $(\mathrm{W})=60.7 \times \mathrm{VJ}(\mathrm{cm})+45.3 \mathrm{x}$ mass $(\mathrm{kg})-2055$.

Calculated by this formula the maximum power at the beginning of the study and at its end were 3345.6 and $4252 \mathrm{~W}$, respectively. As can be seen from this result, the subject had increased her anaerobic capacity of the lower limbs as a result of training and the diet did not affect it.

Our meetings with the gymnast were also used to talk about her feeling during this period of intervention. She was explaining me how she manages to fulfil the recommendations we have made, how the diet plan affected her mood and how she handled her training sessions. This feedback was very important as we were ready to make the necessary changes in case of any problems. The gymnast was positive all the time. Any registered change in her body weight and composition made her even more motivated. She shared that she felt more energy and that she was able to bear her training load every day easier. The training sessions became more enjoyable and she performed the exercises requiring more flexibility better and with greater accuracy and contempt.

\section{Reflections}

The main purpose of this study was to adjust weight without affecting the anaerobic ability of the gymnast. The results clearly show that the person reduced the weight by $2.1 \mathrm{~kg}$ for about one month and the largest percentage being due to the loss of body fat $(61.09 \%)$ and this did not reduce the anaerobic capacity of the gymnast. Due to the short preparation period, the person was not able to prepare well enough to take part in the national gymnastics championship, but the training and the work on weight correction continue. She is at the age when she is still likely to continue her career, so she will probably return to the field soon.

Proper nutrition, ensuring a balanced intake of basic foods, as well as all the necessary vitamins and minerals, can significantly help correcting and maintaining proper weight without affecting the performance of the athlete.

\section{ACKNOWLEDGMENT}

We would like to thank the participant in this research for her confidence in us and her willingness to accept this challenge.

\section{REFERENCES}

1. Marina, M., \& Torrado, P. (2013). Does gymnastics practice inprove vertical jump reliability from the age of 8 to 10 years? Journal of Sport Sciences, 31, 1176-1186.

2. Claessens, A. L., Lefevre, J., Beunen, G., \& Malina, R. M. (1999). The contribution of anthropometric characteristics to performance scores in elite female gymnasts. The Journal of Sports Medicine and Physical Fitness, 39, 355360.

3. Sands, W. A., Slater, C., Mcneal, J. R., Murray, S. R., \& Stone, M. H. (2012). Historical trends in the size of US olympic female artistic gymnasts. International Journal of Sports Physiology and Performance, 7, 350-356.

4. Carter, J. E., \& Heath, B. H. (1990). Somatotyping: development and applications. Cambridge: Cambridge University Press.

5. Bester, G., \& Coetzee, B. (2010). The anthropometric vault item performance determinants of young female gymnasts. The South African Journal for Research in Sport, Physical Education and Recreation, 32, 11-27.

6. Jemni, M. (Ed.). (2011). The Science of gymnastics. Abingdon: Routledge.

7. Kirkova, M., Markov, A., Dzimbova, T. (2019). Development and validation of a new simple food frequency questionnaire for Bulgarians. SocioBrains, 58, 54-57.

8. Sureira, T. M., Amancio, O. S., \& Braga, J. A. (2012). Influence of Artistic Gymnastics on Iron Nutritional Status and Exercise-Induced Hemolysis in Female Athletes. International 
Journal of Sport Nutrition and Exercise Metabolism, 22, 243-250.

9. Heller, J., Tuma, Z., Dlouha, R., Bunc, V., \& Novakova, H. (1998) Anaerobic capacity in elite male and female gymnasts. Acta Universitatis Carolinae: Kinanthropologica, 34, 75-81.

10. Inbar, O., Bar-Or, O., \& Skinner, J. S. (1996). The Wingate anaerobic test. John Wiley \& Sons.

11. Sargent, D. A. (1921). The physical test of a man. American Physical Education Review, 26, 188194.
12. Taylor, M. J., Cohen, D., Voss, C., \& Sandecock, G. R. (2010). Vertical jumping and leg power normative data for English school children aged 10-15 years. Journal of Sports Sciences, 28, 867872.

13. Sayers, S. P., Harackiewicz, D. V., Harman, E. A., Frykman, P. N., \& Rosenstein, M. T. (1999). Cross-validation of three jump power equations. Medicine and Science in Sports and Exercise, 31, 572-577. 